\title{
Intensity-Modulated Radiation Therapy (IMRT) for the Para-Nasal Sinus (PNS) Malignancies
}

\section{Aruna Turaka*}

Department of Radiation Oncology, Fox Chase Cancer Center, Philadelphia, PA, USA

Tumors of the paranasal sinuses are rare among the head and neck cancers and comprises $<1 \%$ of all malignancies. Given proximity to the critical structures such as skull base, central nervous system, optic apparatus and orbits, these cancers pose a therapeutic challenge, particularly because these cancers present at an advanced stages. As majority of these patients at advanced stages, these are treated using radiation therapy with or without surgical resection. In resectable patients, surgery followed by postoperative RT is (64-74 Gy) considered standard by many centers. RT alone (70-74 Gy) along with concurrent chemotherapy is recommended in patients with unresectable disease. Elective nodal irradiation (ENI) is not considered standard due to low incidence of lymph node metastases among these patients except limited data from few centers on ENI for T3-4 stage tumors.

Radiation therapy using conventional techniques has been associated with a number of potentially severe complications, leading to radiation related injury to the visual apparatus. Ocular toxicity is a significant complication among patients treated for PNS tumors and the incidence of unilateral and bilateral blindness from radiation induced retinopathy and optic neuropathy has been as high as $30 \%$ and $10 \%$ respectively [1]. Published data showed poor local control rates for paranasal sinus malignancies with radiation therapy using different RT techniques due to the difficulties of air tissue interface

\begin{tabular}{|l|l|l|l|}
\hline Institution & $\begin{array}{l}\text { No. of } \\
\text { patients }\end{array}$ & $\begin{array}{l}\text { 5-year Local } \\
\text { control rate }\end{array}$ & $\begin{array}{l}\text { 5-year Overall } \\
\text { survival }\end{array}$ \\
\hline $\begin{array}{l}\text { Duprez F, Ghent Univ, } \\
\text { Belgium (2) }\end{array}$ & 130 & $59 \%$ & $52 \%$ \\
\hline Wiegner EA, UCSF (3) & 52 & $64 \% *$ @ 2 years & $66 \%$ @ 2 years \\
\hline Cattaneo R, FCCC (4) & 31 & $82 \%$ & $66 \%$ \\
\hline
\end{tabular}

*Loco-regional control rate at 2 years

Table 1: Local control and survival rates. interactions as well as the close proximity to the optical apparatus. Intensity-modulated radiation therapy (IMRT) offers the potential to reduce dose to critical structures while maintaining desired doses to the gross tumor volume via optimized non-uniform beam intensities $[2,3]$. Various studies reported improved clinical outcomes of PNS tumors treated with IMRT with excellent local control and survival rates with minimal complications including our experience at Fox Chase Cancer Center (FCCC) [4]. 31 patients with PNS malignancies were treated at FCCC with IMRT to a median dose of $60 \mathrm{~Gy}$ in 30 fractions. Median RT values to optic apparatus: Optic chiasm $\mathrm{D}_{\text {max }} 22 \mathrm{~Gy}$ (range: 1-48); right and left optic nerve $\mathrm{D}_{\max }$ were $39,37 \mathrm{~Gy}$ (range: 2-62; 2-65). At a median follow up of 27 months (range: 4-98), the 2 - and 5-year local control and overall survival rates were $89 \%, 82 \%$ and $75 \%, 66 \%$, respectively (Table 1). The 2-year loco-regional control rates were $89 \%$ for stage I/II and $79 \%$ for stages III/IV. There were no grade 3 or 4 ocular or salivary function related toxicities in our experience. IMRT appears to be a safe, effective treatment for para-nasal sinus malignancies.

\section{References}

1. Pacholke HD, Amdur RJ, Louis DA, Yang H, Mendenhall WM (2005) The role of intensity modulated radiation therapy for favorable stage tumor of the nasal cavity or ethmoid sinus. Am J Clin Oncol 28: 474-478.

2. Duprez F, Madani I, Morbée L, Bonte K, Deron P, et al. (2012) IMRT for sinonasal tumors minimizes severe late ocular toxicity and preserves disease control and survival. Int J Radiat Oncol Biol Phys 83: 252-259.

3. Wiegner EA, Daly ME, Murphy JD, Abelson J, Chapman CH, et al. (2012) Intensity-modulated radiotherapy for tumors of the nasal cavity and paranasal sinuses: clinical outcomes and patterns of failure. Int J Radiat Oncol Biol Phys 83: 243-251.

4. A Turaka, R Cattaneo, N Nicos, M Lango, B Burtness, et al. (2010) Intensitymodulated radiation therapy (IMRT) for the Para-nasal sinus malignancies: Outcomes from Fox Chase Cancer Center (FCCC). Int J of Radiat Oncol Biol Phys 78: S 478-S479. *Corresponding author: Aruna Turaka, Assistant Professor, Department
of Radiation Oncology, Fox Chase Cancer Center, 333 Cottman Avenue,
Philadelphia, PA 19111, USA, Tel: 215-728- 3022 ; Fax: 215-214-1629; E-mail:
aruna.turaka@fccc.edu

Received June 06, 2013; Accepted June 08, 2013; Published June 10, 2013

Citation: Turaka A (2013) Intensity-Modulated Radiation Therapy (IMRT) for the Para-Nasal Sinus (PNS) Malignancies. J Nucl Med Radiat Ther 3: e109. doi:10.4172/2155-9619.1000e109

Copyright: (c) 2013 Turaka A. This is an open-access article distributed under the terms of the Creative Commons Attribution License, which permits unrestricted use, distribution, and reproduction in any medium, provided the original author and source are credited. 